\title{
THE PROBLEM OF BUILDING CODE IMPROVEMENT
}

\author{
GEORGE N. ThOMPSON*
}

In recent years there has been a mounting chorus of criticism about building codes. They have been blamed for increased construction costs, inability of new materials to gain a footing in the construction field, and numerous other undesirable conditions. Statements about them have sometimes been so unfavorable as to cause concern among thoughtful people that public confidence in measures to assure public safety would be seriously undermined. Of late, a slight reaction is beginning to appear to the effect that, after all, many codes are doing a fair job. Whatever the magnitude of their merits or defects, it becomes apparent to anyone who gives much attention to the matter that here is a subject of much importance to the construction industry as a whole and currently to that considerable part that is giving its best efforts to relieving the shortage in housing.

The background is simple. Experience has proved that government must act in protection of the public to control the operations of the ignorant, the incompetent, and the unscrupulous in the construction field. Fire, collapse, and other sources of injury and even death traceable to imperfect construction occur frequently enough to remind us that trouble can occur even when regulations are in effect to prevent it. What could happen in the absence of such regulations, or in the event of regulations so weakened that they become inadequate, can readily be imagined. So the state steps in, exercises its police power, and attempts to furnish reasonable safeguards.

Workers in the field of building code improvement become accustomed to periodical rediscovery of the subject by others and recurrent demands for sweeping changes which will somehow accomplish a variety of things. They welcome these manifestations of interest for, when no serious disasters are occurring and no economic convulsions are creating demands for drastic measures of all sorts, relatively little interest is displayed in the subject by the general public. It is not always easy, however, when interest is keen to explain the nature of the problems that must be faced and the complicating factors that must be satisfactorily adjusted before a quickening in the rate of progress of improvement is possible. The problems are in part technical,

- A.B., Harvard University. Chief, Division of Codes and Specifications, National Bureau of Sandards, U. S. Department of Commerce; Chairman, Building Code Correlating Committee, American Standards Association; Chairman, ASA Sectional Committee A58 Building Code Requirements for Design Loads in Buildings. Formerly Associate Director, Research on Slums and Housing Policy sponsored by the Phelps-Stokes Fund of New York City, 1933-r934; Chief, Building Codes Section, Division of Building and Housing, National Burcau of Standards, 1926-1933. Author of The Preparation and Reviston of Burloing Codes, issued by the National Bureau of Standards, and of numerous articles on building code matters. 
in part legal, and in part administrative, with the usual blurring of lines between them that characterizes all governmental undertakings.

Writers on the subject are fond of starting with Hammurabi, who ruled over Babylon more than two thousand years before Christ with the harshness of an Oriental despot. This approach has become so much the vogue that we must dispose of him before we can expect to enter any serious discussion of the subject. It is true that he did promulgate a building code of a sort, the fact being duly recorded on burnt-clay tablets, and that for simplicity and probable effectiveness it has not been surpassed to this day. ${ }^{1}$ Speaking generally, the principle of an eye for an eye and a tooth for a tooth prevailed in it. If a builder constructed a house which fell down and killed the occupant, the builder was to be put to death, ${ }^{14}$ and so on. While this system undoubtedly had its good points, we must turn from it regretfully without further comment to those measures which fit more nearly the governmental system under which we find ourselves today.

This system is one in which, by law and tradition, the Federal Government has up to the present occupied a secondary place. Only in areas where it had original jurisdiction, as in the District of Columbia, has it attempted to deal directly with those questions of safety, health, and welfare which concern the occupants of buildings and those who for some reason or other are affected by the multifarious hazards which those inanimate objects are capable of producing. In an advisory way, however, its influence has been considerable.

This situation helps to explain many of the conditions that exist today in the building code field, in particular the lack of uniformity in requirements. Some of the differences that are evident might be expected to proceed naturally from diverse conditions in a great country arising from differences in climate, variations in type and quality of building materials, and other factors that come readily to mind. A great deal, however, arises from the fact that half a dozen states and more than two thousand municipalities have at different times and with different sources of information attempted to set down their individual concepts of what constitute sufficient safeguards in construction. The result could not be otherwise than a medley of requirements involving a considerable range of provisions about the same thinge, sometimes even resulting in neighboring cities permitting and forbidding the same practices.

As has already been indicated, realization of this fact periodically proves shocking to each new group of investigators whose attention is temporarily riveted on the subject for some reason or other. Comparisons of codes can easily be made which show a considerable range in requirements and even some absurdities. This sort of operation is not very fruifful, however, for it merely calls attention to a situation already known and admitted. The same sort of thing could be done with many other state and local laws on many subjects, the net result being a recitation of

${ }^{2}$ R. F. Harper, The Code of Hasarurari (University of Chicago Press, 1934).

1s. Id. at \$229. 
variations that might or might not be susceptible of reduction depending on many things, including constitutional provisions, judicial decisions, local peculiarities in climate and other respects, and similar factors. Like the existence of Hammurabi's code, the circumstance may be recorded here without argument or further comment, since it is not likely that much could be added to illustrations that have already been given by other writers.

The important question is what can be done constructively to ameliorate the situation within known limits of legal principles, technical knowledge, and administrative competency. This includes an inquiry as to what has already been done and is in process, since it is hardly conceivable that the matter has been wholly neglected over a period of years by intelligent people necessarily aware of the circumstances. It calls also for sympathetic understanding of the fact that many problems which appear at first glance to be relatively simple prove, when analyzed, to resemble the vitamin B complex in that they turn out to be an assortment of items each of which has to be recognized and evaluated.

Let us start with some brief mention of what has taken place over a period of years in the way of work on approach to more uniform requirements. Omitting the developments between Hammurabi and the year rgo5-and there were in fact a number of such developments in which the increasing complexity of the problem is recognized-mention may be made of the Recommended Code of the National Board of Fire Underwriters which first appeared in that year and has maintained an existence ever since in successive editions of which the fifth, in 1943, is the latest. Although never represented as something to be taken without adaptation to local conditions, it has nevertheless been widely consulted and extensively used, either unchanged or in modified form. Necessarily, it has reflected the viewpoint of those whose chief preoccupation is the ravages of fire, but its recommendations have not been limited to that subject and its influence has been considerable.

In the early 'twenties, the Federal Government began to show an interest in the subject that has continued and become intensified down to the present day. In the report of the Senate Committee on Reconstruction and Production, ${ }^{2}$ of r92I, the multiplicity and diversity of building code requirements was treated at some length, with particular emphasis on the economic consequences involved. A significant result was the setting up of the Department of Commerce Building Code Committee, appointed by Secretary of Commerce Hoover in 1921, which maintained an existence to 1934 and was responsible for eight reports ${ }^{3}$ which were widely used in

${ }^{2}$ SEN. REP. No. 829, 66th Cong., 3rd Sess. (rg21. Report of the Select Committee on Reconstruction and Production).

'U. S. Dep't of COMM., Bunlding Code Comm. Reports on: Recommended Minimum Requirements for Small Dwelling Construction (1932); Recommended Minimum Requirements for Plumbing (1932); Recommended Minimum Requirements for Masonry Wall Construction (1924, supp. 193I); Minimum Live Loads Allowable for Use in Design of Buildings (1924); Recommended Practice for Arrangement of Building Codes (1925); Recommended Building Code Requirements for Working Stresses in Building Materials (1926); Recommended Minimum Requirements for Fire Resistance in Buildings (1931); and Design and Construction of Building Exits (1935). 
that period both in recommended building codes and in local ordinances. The recommendations thus made available had a firm base in a large amount of research carried on by the National Bureau of Standards which also furnished the committee's staff and published its reports. The auspices under which this work was conducted and the quality of its product were responsible for the high degree of public confdence that was shown in it.

Not long after the establishment of this committee, the Pacific Coast Building Officials Conference undertook the preparation of its Uniform Building Code which has appeared at intervals ever since, and has been widely used, and is now available in an edition published in 1946. Other organizations of building officials, notably the New England Building Officials Conference and the Southern Building Codes Congress, have issued recommended codes; and the Building Officials Conference of America is now engaged upon a similar enterprise.

In 1935 work on the preparation of a complete series of building code standards was undertaken under the direction of the Building Code Correlating Committee of the American Standards Association ${ }^{4}$ and this has continued to the present, standards having been approved on the subjects of building code administration, masonry, structural steel, reinforced concrete, reinforced gypsum concrete, design loads, and exits, with others in an advanced stage of development. In this undertaking, representative technical committees, drawing their membership from various interested organizations, attempt to arrive at a consensus which will provide generally acceptable standards.

This brief account does not exhaust all the approaches that have been made to the problem of better and more uniform requirements. In fact, occasional mention will be made of other work as this discussion proceeds. It is hoped, however, that it will dispel any impression that serious work on building code improvement has been neglected. The reverse is true. Perhaps the most pertinent observation that might be made with respect to the activity that has gone on and is proceeding at present is that further correlation of independent recommendations would be desirable in the public interest.

It should be stated that this work in the building code field profits greatly from a vast amount of research, testing, and discussion growing out of the work of various professional societies, university laboratories, and other sources of scientific information. What we know about the characteristics of building materials today and are able to utilize in writing regulations concerning their use is derived from the reports of many patient investigators who have built up a stock of information upon which to base decisions. Mention should also be made of the efforts of material manufacturers to provide facts about their products. While it is natural to regard such activities as promotional in type and therefore to be viewed with reservation, it is nevertheless true that this form of intelligent selfishness, if it may be called such, has been responsible for a vast amount of helpful information.

\footnotetext{
- See Amer. Standards Ass's, Building Code Standardization (pamphlet issued by the Association in 1944 and distributed by the American Municipal Association).
} 
In spite of all that has been said about the construction industry as a sprawling group of uncoordinated and wasteful activities which somehow produces structures of doubtful value, there has nevertheless been a great deal of progress in this field. It could hardly be expected that this progress would be otherwise than gradual, considering the great investments in manufacturing plants, the lack of knowledge both about the fundamental characteristics of the materials employed and the forces to be resisted in ordinary use, and the need for keeping within safe limits in order to prevent disasters. Impatience with the faults of the industry is understandable; but sober thought will indicate some justification for the caution with which materials have been employed.

Impatience has been intensified in recent years and the pace of acceptance of new methods has been quickened, again for understandable reasons. We are now building upon the results of a past in which research has contributed a great many facts that we did not know before. Mistakes have been made which can be evaluated and avoided in the future. Techniques of application have been improved up to the point where results can be predicted with much greater assurance than a score of years ago.

For confirmation of these statements it is only necessary to refer to a few of the materials in common use today which were the "new" materials of a previous generation or not much before its time. Take the case of structural steel, an interloper of the 'eighties, thrusting aside cast-iron structural members but accepted with reservations because of occasional uncertain behavior. Made at first by the Bessemer process, its quality and reliability have been steadily improved until today it is regarded as one of our more consistently reliable materials. Reinforced concrete, an intruder at the beginning of the present century, was viewed with suspicion and probably justifiably so at first because much had to be learned about its design, methods of mixing, and other details. Unrelenting research has provided a storehouse of knowledge which has established confidence in this material and accounts for its widespread use.

These earlier struggles of materials now well accepted and fully covered in building regulations are sometimes forgotten when the slow rate of acceptance of new materials today is under discussion. It is often contended that promising new developments are being discriminated against when, in fact, they are merely experiencing the growing pains which older materials have suffered.

Complacent acceptance of the thesis that all new materials must wait respectfully for their turn and be approved only after a long and rigorous apprenticeship is not, however, in accord with the spirit of the present times, nor is it justified in the light of present knowledge. The view is becoming accepted that it should be possible to tell fairly accurately what is expected of a given element in a structure and that it should be possible to investigate new materials in such a way as to determine without long delays whether they are capable of doing what is claimed for them. The long periods of trial and error that have prevailed in the past should thus be cut 
down through laboratory tests intended to provide necessary information upon which acceptance or rejection may be based. Correlation of laboratory results with field experience is admittedly not always easy, but much progress is being made along this line.

This development has tended to create a disturbance in the older quiet waters of code writing, with ever-widening ripples as more fundamental facts are assembled and studied. The old methods of calling arbitrarily for so many inches of brickwork or concrete around steel columns as fire protection, thicknesses which may have given approximately equal results in some cases but certainly not in others, has been giving way to a method of statement in which hours of protection afforded are the controlling consideration. It is possible to do this, not because code writers have evolved some mysterious phraseology that outmodes the work of their predecessors, but because a standard method for conducting fire tests ${ }^{5}$ has been laboriously cvolved by a committee of the American Society for Testing Materials, has been approved by the American Standards Association, and has become the accepted method for determining the fire resistance of structural members and other elements entering into a building. As a result of many tests conducted in various laboratories, the fire resistance of many materials has been definitely determined. Here is an excellent demonstration of the interdependence of the code writer, the professional society, and the scientific laboratory.

There is work yet to be done to make performance rather than specific materials and methods the basis for code requirements. Another committee of the American Society for Testing Materials is probing a field in which standard test methods are as yet lacking. This is a matter of general interest to those engaged in housing, because it is concerned, among other things, with how to determine the strength and other characteristics of structural assemblies which cannot be evaluated through conventional engineering methods. Take, for instance, the matter of prefabricated construction. In many cases this consists of panels pre-assembled into convenient sizes for quick assembly at the site. Much has been written about the reluctance of building officials to accept such construction, and yet it is obvious that no responsible official can approve it in its many manifestations without adequate proof of its safety. The problem then becomes one of accumulating evidence which will demonstrate beyond a reasonable doubt just what the construction is capable of doing. Here the standard test method looms up as a comfortable guide which can answer many questions and place the whole matter on a sound basis. It is for this reason that the early completion of standard test methods having responsible authorship is to be looked forward to as filling a real need.

The problem that confronts local authorities when it becomes apparent that existing code requirements are no longer working satisfactorily is one of great interest. Theirs is the responsibility of providing just enough restrictions on the way in which

\footnotetext{
- Amer. Soc. for Testinc Materials, Standard Methods of Fire Tests of Building Construction and Materials (ASTM Designation: Cig-4I).
} 
materials may be used to assure safety for building occupants, but just what constitutes adeqaute safety is none too well defined and many differences of opinion are possible. An extreme solicitude for safety may increase the costs of construction to such an extent that building activity is discouraged. Particular emphasis on some phase of safety, such as fire protection, may bring protests from manufacturers of products that their materials are discriminated against and that a true interpretation of the hazard produced by their products has not been made. The possible unpleasantness arising from such representation, coupled with the labor and expense involved in producing a new code, accounts for much of the reluctance of local authorities to act and consequently for the lag that is only too apparent in efforts to keep codes up to date.

In facing the problem squarely and intelligently, however, there are certain aids available in code writing which help to reduce the apparent diffculties. These include the great array of facts to be found in reports embodying the results of research carried on in recent years. They include also the accumulated experience of local architects, engineers, and others whose knowledge of what is locally available and how it is likely to be put together is invaluable. Probably the most significant development in the field of code requirements, however, is the growing number of reference standards that are available. These are the product of standardizing bodies, professional societies, and other organizations, and embody the composite judgment of representative national committees applied to the facts contained in results of laboratory research and to accumulated practical experience. They do not necessarily supply the one and perfect answer to all questions pertaining to safety in construction; but probably they provide as close an approximation to agreement as can be reached by competent and disinterested authorities. They include standards of quality for building materials and standards of good practice in the design and installation of the materials or combinations of them.

The growing number of these standards has helped to reduce some difficulties in code writing but has raised other questions at the same time. The mechanics of code writing consists not only in chosing the right technical content but in presenting it in a way which is legally enforceable. The standards that have been mentioned are developed by private organizations and must be taken over in some way into law before they can have any effect. The skill with which this is done determines to a very large extent the future effectiveness of the code.

Mention has been made of the standards developed by committees operating under the procedure of the American Standards Association. The work carried on by these committees is of considerable interest because it represents an attempt to bring together the various organizations that are concerned with the problem in order to achieve a common understanding on what is necessary in the way of standards in this field. Under a Building Code Correlating Committee, composed of representatives of organizations having a general interest in all phases of the subject, are some fifteen sectional committees. These deal with such matters as design loads, fire 
protection, exits, light and ventilation, and structural materials. Each is under the immediate direction of a sponsor or sponsors consisting of the organizations most definitely identified with the subject and its membership is made up of representatives of other organizations which are in a position to make a contribution. Work is carried on through discussion of drafts of proposed requirements until the desired consensus is reached. Eventual completion of a complete series of such standards should provide the groundwork for generally acceptable basic requirements, so far as it is possible to obtain agreement upon them.

Anyone who has taken the trouble to examine building codes knows that many of them refer to certain standards, often with very sketchy identification and as amended from time to time. The purpose, of course, is to take advantage of the existence of reliable engineering material in its most. up-to-date form. In a journal devoted to problems of law, it is hardly necessary to point out that such codes violate sound principles and would hardly meet with favorable treatment if tested in the courts. Nevertheless, the fact that such references are made is indicative of a need that is felt for some way to make use of the best technical recommendations available and in their latest form. It is no solution to state with finality that the method of reference employed is legally indefensible. The need still remains.

So code writers are confronted with a rich storehouse of information organized in readily usable form and kept current by the organizations that have produced it, and yet ways of using it to the best advantage are clouded by questions of certainty and delegation of legislative authority.

In the face of this problem, code writers have reacted differently. The majority have preferred to take the conservative course of citing a standard and identifying it definitely by the year of its adoption by the parent society. Some have avoided references almost altogether and have copied what they thought would be the essential features of the standard into the language of the codé. Others have launched out with various experiments, such as requiring good engineering practice, and then citing a given standard as acceptable under the requirement. Still others have experimented with conferring the power to make rules upon the building official or upon a board and indicating that he should be guided by national standards which he can make concrete in his rulings.

What is desired, of course, is some way through which latest authentic standards may be employed as means of control without the necessity of continual recourse to the municipal council to make the use of later editions valid. The efforts may be clumsy and often of doubtful effect; but the intent is plain. One suggestion that offers some promise is a mandatory provision in the administrative provision of the code requiring the building official to bring a revised list of standards before the council at periodic intervals for adoption. Experience has proved that unless some such procedure is followed the references in the code soon become obsolete.

So much attention has been paid to technical matters and so much pressure for accomplishment has been placed upon local authorities once code preparation or 
revision has been started that serious work on fundamental theory has been more or less neglected. With the availability of a complete series of reference standards in sight and with a better appreciation of problems arising in the utilization of such standards, it is becoming apparent that time could profitably be spent on ways of making such standards fully effective.

It is possible to conceive of a code consisting, aside from its administrative chapter, of a series of references to designated standards, followed in each case by further provisions giving such additions, modifications, or exceptions as the local authorities might consider advisable. Such a code would be compact, uniform in general treatment with other codes, and presumably would reflect the best possible technical information that could be obtained.

It is quite probable that such a treatment would meet with objections on several grounds, although logically it would have much to commend it. It presupposes acceptance of the principle that adoption by reference is a desirable procedure and this will be resisted for a number of reasons, both legal and practical. Among the latter will be the contention that to find out what is really required the reader must resort to a perusal of numerous standards rather than get his information at first hand in the code. This is an objection that will appeal to many; and yet it is a fact that many codes already represent a partial adoption of the principle, with no perceptible difficulty.

To meet such objections, a method of statement has been proposed in which those features in the standard that are relatively important from the standpoint of safety, and hence presumably might well be passed on directly by the munieipal authorities, are given in the code in addition to the reference to the complete standard. The result is the repetition of considerable matter already to be found in the standard, with some gain in convenience but with the necessity still remaining to consult the standard itself in order to observe all details.

From what has been said, it is apparent that serious work on the development of technical standards is actually in process. It should not be inferred from this, however, that the rate of progress in making such standards available for use is always as good as might be desired nor that the mere existence of such standards constitutes all that is necessary to make building codes satisfactory. Committee work on developing recommended requirements often brings out points of controversy where wellqualified persons find themselves unable to reach an immediate agreement. The tedious process of adjustment of views must be gone through with, and meanwhile a yawning gap in the structure of reasonably uniform requirements remains unfilled. It cannot be said, however, that so far as the technical side of the problem is concerned, there is any lack of machinery for resolving of difficulties. The chief criticism to be advanced here is that efforts might well be accelerated in the public interest.

The question has been raised more than once whether the present pattern of more than two thousand separate local codes could not be replaced by some more 
logical system in which a single set of technical requirements based on national standards would be varied only to the extent necessary to meet special local conditions. Such an arrangement undoubtedly would have many advantages for the growing number of concerns which sell building materials over a wide area or, as is becoming more prevalent, market complete houses of the prefabricated type. It would also no doubt be welcomed by the many designers and builders who do a country-wide business. It seems hardly likely that acceptance of such an arrangement is to be expected in the near future, for varying state laws, local traditions, and genuine differences in local needs offer too great a handicap. However, each revision of a local code tends to bring it into greater uniformity with others because of the common use of basic material. A comparison of a group of local codes ten or fifteen years ago with their successors today demonstrates clearly that the approach to reasonable uniformity, if slow, is nevertheless in process. It has been accelerated through the use of proposed uniform codes developed by organizations of building officials as well as by the availability of the national standards to which frequent reference has been made.

While there are obvious difficulties in achieving greater uniformity on a countrywide basis, the chances of making progress in this direction within a given state would seem to be much better. A state-wide code, with due allowances for necessary local differences mostly of an zadministrative nature, has much to commend it. Yet, with few exceptions, the states have preferred to delegate the matter to the municipalities through enabling acts or charter provisions. At times they have adopted miscellaneous legislation applying to such things as exits for places of public assembly and industrial establishments; but in the main the municipalities have carried the major responsibility. In Ohio, Indiana, Wisconsin, and a few other states, actual state codes exist. That in Wisconsin has a long record of successful administration, its terms like those of most state codes do not apply to one- and two-family houses. It presents, however, an interesting application of the principle of entrusting the preparation of detailed requirements to a state commission which may modify them as time goes on without recourse to the legislature. This delegation of authority has apparently worked well and has provided an effective means of making necessary technical adjustments with the passage of time.

Picard, ${ }^{8}$ in discussing this use of delegated legislative power, points out that it has become well established as a means of dealing with technical details in accordance with policies and standards laid down by the law-making body. There is much to be said for its more extensive application in the form of state building codes prepared by boards having technical competence and administrative ability. Greater uniformity in requirements over a considerable area, responsiveness to new developments in the construction art, and centralized testing and acceptance of materials are all possible under such an arrangement. Studies being conducted in a number of states by official bodies indicate that these advantages are becoming appreciated and

- Prcard, Essentiats in Safetr Code Maxino (1938). 
that additions to the relatively small number of state codes now in existence may be expected. However, it is to be expected that any trend of this kind will be gradual and that the municipal type of code will be the prevailing one for an indefinite period.

The wisdom and resourcefulness with which building officials apply the terms of the code are highly important and yet most discussions of building codes have little to say on this point. Control of building operations starts with the application for a permit, extends through the granting of this permit on approval of plans, involves inspection of work under way, and includes issuance of a certificate of occupancy for most structures, although this is not usually the case where housing is concerned. At many points along the way the building official must make decisions. If the plans show construction not conforming to the code, the application for permit may be rejected. If, during the course of construction, work is found to be at variance with some code requirement, a stop order may be issued. Evidence of willful violations may be turned over to the municipal legal department for prosecution, which may result in a fine for the violation; the issuance of a certificate of occupancy may be held up when final inspection discloses unsafe conditions.

It will readily be seen that there can be many occasions where difficult decisions must be made. Buildings do not fall into stereotyped patterns and code requirements can never be all-inclusive. As a result, interpretations of the code applying to particular cases must be made and slight deviations must be weighed to determine whether the spirit of the requirements is being observed. In many cases the literal terms of the code make no allowance for such actions, but it is generally conceded that they take place as a matter of practical administration. If this is the case, it would seem better to provide for some exercise of discretionary power in the code rather than to have its requirements relaxed without definite limitation. It is, of course, evident that the official cannot make law and that any rulings he may issue must be such as to remain clearly within its intent.

It is only fair to say that the granting of considerable discretion to the building official in the exercise of his duties is not always looked upon with favor. Burton ${ }^{7}$ has questioned the practice and he has been joined by others who see in it the possibility of favoritism. Miller, ${ }^{8}$ however, has consistently advocated the exercise of discretionary power, contending that its use is inevitable whether officially recognized or not and that inability to exercise it reduces the official to the status of a mere clerk, incapable of dealing intelligently with situations as they arise.

Whatever the degree of discretion exercised, there will always be situations where differences of opinion arise between the official and those who desire to undertake building operations. Infallibility in the interpretation of code requirements is not possible. Wisely, many municipalities have made provisions for boards of appeal before which grievances may be aired and by which capricious and arbitrary actions

\footnotetext{
${ }^{7}$ F. Burton, Some Legal Aspects of Building Codes and Their Enforcement (1924) Procendngs, ioth Annual Meeting of Butlding Officials Conference of America 94.

R. P. Miller, Economic Housing as Affected by Building Codes (Appendix to Report of the Com. mittee on Construction, President's Conference on Home Building and Home Ownership, I93I).
} 
of an official may be corrected. In some cases, these boards pass upon proposals for use of new materials and methods of construction. In others, they hear appeals from the building official's rulings on these matters. When authorized by state law, they grant variations from the strict terms of the code in cases of hardship or manifest injustice due to special conditions.

The desirability of having such boards of appeal has been recognized in a number of recommendations, including the standard for administrative requirements developed under the procedure of the American Standards Association. ${ }^{9}$ Here a five-man board is recommended to which is assigned the duty of hearing appeals and rendering prompt decisions on the question at issue. A person aggrieved by the decision of the board may apply to the appropriate court to correct errors of law in the board's decisions.

The recent report of the Chicago Association of Commerce (prepared by the John B. Pierce Foundation), on the building code situation in Chicago, ${ }^{10}$ lays emphasis on the need for a definite appeals procedure and proposes the unusual arrangement of two boards, one to hear appeals and the other to pass upon the merits of new materials and new methods of construction, formulate rules, and propose amendments to the code. Such an arrangement seems hardly necessary. New York City has had a Board of Standards and Appeals for many years, which, although subject to various vicissitudes, ${ }^{11}$ has, on the whole, apparently performed acceptably with respect to both functions. Picard ${ }^{102}$ points out that the experience gained by a board in studying appeals makes it peculiarly suited to developing suggestions for changes in the code, since it has first-hand knowledge of troubles that develop.

Although some difficulty may be experienced in smaller communities in finding qualified men to make up boards of appeal, the importance of this link in the system of building regulation is so great as to warrant unusual efforts in getting the necessary persons to serve. It provides a relatively inexpensive and prompt method of correcting errors in judgment on the part of the building official. Any accumulation of cases brought before it serves as a danger signal that certain parts of the code may need amendment. Its efficient functioning can do much to create public confidence in the manner in which the community provides for safety of building occupants.

With respect to the possibilities for further refinements in building code requirements applying to dwellings, there is much to be done, even though much has already been done to remove excessive and inconsistent provisions. As a matter of fact, the loads and forces to which such structures are subjected are not any too well known even after many years of living in them. We have come a long way in this country from the huge hand-hewn timbers of the colonial era to the relatively fragile

\footnotetext{
- Amer. Standards Ass'n, Administrative Requirements for Building Codes (A55.1-1944). (A revised edition of this standard is in preparation.)

${ }^{30}$ Building Regulation in Chicago, An anazysis and Recommendations (presented by the Chicago Association of Commerce, Nov., 1945).

${ }^{11}$ John C. COMER, NEW YorK CITY BuILDINo Control, I800-1941 (1942).

${ }^{102}$ Op. cit. supra note 6 .
} 
two-by-four studs and two-by-eight or ten-inch joists of the present era in woòd construction; and yet it is not certain that this paring down process has reached its ultimate limit. We need to know more about snow loads, how wind acts upon walls and roofs, and how loads are distributed, to make requirements for various structural members in a house.

Similarly, the characteristics of building materials have not been fully explored, despite the intensive research that has been devoted to them, and new ways of using them are being devised. Improved processes of manufacture make it possible to place greater dependence upon many materials than before. Applications of new materials and combinations of them with conventional types are introducing new ways of building houses. As a result, adjustments in building code requirements must be made periodically.

As evidence of progress may be cited the increased attention that is being paid to the way in which wind acts upon the walls and roofs of buildings. The great majority of codes have dealt with this matter very sketchily; and the fact that relatively little trouble has been experienced has probably been due to liberal assumptions as to wind loads and liberal amounts of materials used in construction. As the size of structural members is reduced for reasons of economy, however, a great deal more thought has to be given to possible effects of wind. It is fortunate that these effects are becoming better understood so that provision can be made for them. Most code requirements have been based upon the assumption that wind pressures, on both walls and roofs are always inward; whereas it is now known that outward pressures are entirely possible, a fact that helps to explain the occasional departures of roofs in strong windstorms. So-called negative pressures on the leeward side of a building must also be taken into account.

Considerable discussion also develops around the conventional requirement of forty pounds per square foot as the assumed load on dwelling floors as a result of the weight of furniture and occupants. Values as high as one hundred pounds have appeared in codes in the past but the figure of forty pounds is now very general. It can be shown that in many houses the load involved does not run much above ten pounds per square foot. Admittedly, however, there may be occasional increases in load due to such events as cocktail parties and some examples of concentrated loads will come to mind. Still, the difference between ten and forty pounds is so great as to cause occasional recommendations that thirty pounds is ample as an assumption, especially if the possibility of a concentrated load at any point on the floor is provided for. Such recommendations indicate that the final answer may not yet have been reached in what might appear at first glance to be a very simple problem. It is noticeable in all such cases, however, that suggested changes become smaller and smaller as time goes on.

Associated with closer approximations of loads are increases in working stresses for building materials. Both tend to reduce whatever margin of safety may have been present in earlier requirements. Within the last twenty years, allowable stresses 
for structural steel have increased from sixteen to twenty thousand pounds per square inch, with at least one city permitting twenty-four thousand. Similarly, recommendations spoinsored by lumber manufacturers represent an increase of twenty percent in allowable stress over that permitted in most codes, provided material that is carefully graded for stress value is used. Allowable stresses in reinforced concrete, predicated on the use of accurate mixes and controlled water content, have also shown a tendency to increase with the passage of years These are only examples of a more or less general tendency toward more economical use of materials when specified conditions of quality are observed. It is apparent that they represent a trend which necessarily has a limit in each case, although how close this limit may be approached is still uncertain.

Developments in prefabricated construction have brought about more attention to application of principles of structural design of houses. Where economy in use of materials and lightness of product in order to hold down freight charges are important factors, real engineering design is necessary. The resulting products, although in most cases amply strong for the purpose intended, have appeared flimsy to many observers. Not being provided for specifically in many codes, the burden of proof has rested on their sponsors that they comply with safety requirements.

There is a general impression that such products are shut out of consideration by most codes. Actually, a large number of codes deal with the matter of acceptance of new materials and new methods of construction in their administrative chapters by conferring upon the building official or on a board the power to approve upon submittal of sufficient evidence that the innovation is safe.

Since these provisions are general in character and leave a great deal to the discretion of the local authorities, the chances of varying, and even prejudiced, treatment are always present. Obviously, the new material or construction has no special claim to attention just because it is new. Neither should it suffer from a handicap on that account. The problem is to provide a machinery that will assure it prompt and impartial consideration on its merits. This involves four steps-a suitably worded provision in the code, standard methods of testing to assure uniform treatment, uniform methods of evaluating the results of tests, and a competent board to act as occasion requires.

A good deal has been said in discussions of building codes about the existence of provisions that have been inserted for selfish motives by groups which might be expected to benefit from them. Undoubtedly such requirements exist, although it is not always possible to say with assurance just how much self-interest and how much honest difference of opinion are responsible. The correction of conditions of this nature is a local problem and the pressure of enlightened public opinion is necessary to accomplish desirable changes. The existence of national standards such as have been described should prove to be of material assistance, however, since a basis for comparison is at once established and the objectionable local requirement can be placed upon the defensive. 
Any constructive approach to the building code problem today must recognize the factors that have been described. There must be available sound reference standards which take into account the great amount of information that has accumulated and is still accumulating as the result of research. The evolution of these standards, if they are to be universally acceptable, requires arrangements for obtaining composite judgment and adjustment of views on the part of persons whose knowledge and experience are such as to command respect. With the content thus established on the basis of scientific fact and collective judgment, the problem then presents itself of how to make new technical contributions immediately effective either through the terms of the code itself or by authorized administrative action. Finally, there is the ever-present problem of assuring competence and impartiality in enforcement by building departments that are generally understaffed and inadequately financed.

The situation is far from hopeless, however. Standards are being produced, if perhaps too slowly, that are finding their way into use and are supplying the needed basis for comparison with existing requirements of doubtful value. The amount of hard, gruelling work that is put into this feature of the problem. is little known or appreciated. The extent to which code provisions tend to fall behind progress because of the necessity of adhering to legal requirements is being studied and promising ways of overcoming this difficulty are being advanced. Probably there has never been a time when more intensive work was being devoted to development of recommended requirements by organizations of building officials. The various committees acting under the procedure of the American Standards Association are being urged to accelerate their work in order that standards produced through this cooperative work may be available. The National Bureau of Standards, which for a quarter of a century has been looked to as a central source of unbiased information in this field, is continuing its work of evaluating research and the drafting of recommendations. The Construction Division of the Department of Commerce has interested itself in the promotion of good requirements, realizing the beneficial economic effects to be expected. ${ }^{12}$ The National Housing Agency is paying special attention to improved provisions bearing upon residential structures. ${ }^{13}$ All these activities point to a thorough sifting of existing requirements and the substitution of more rational ones, where this is necessary.

This very-intensity of interest and multiplicity of effort will make it necessary to do some very careful coordination. Slight differences in treatment suggested by various organizations will somehow have to be adjusted if the full advantages of 2 reasonable degree of uniformity are to be realized. Real statesmanship and strong leadership may be necessary to persuade all interested organizations to give up any pride of authorship or sense of prior interest in the field in order that the public

12 Mayes, Building Code Improvement. (July, 1946) 34 Domestic Commerae 52.

1s The National Housing Agency is understood to be preparing a revision of a report "Recommended Building Code Requirements for New Dwelling Construction," issued sometime ago under the auspices of the Central Housing Committee. 
may be better served. We have come so far, however, in dealing with the problems involved, that any further necessary adjustments to produce results of greatest usefulness may be confidently expected to follow as a matter of common sense and public responsibility.

In summary, it may be said that the defects of building codes are well understood, that constructive efforts are under way to correct them, and that, with proper understanding and encouragement, efforts in this direction may be expected to greatly improve the structure of public safety regulations in this country. Perhaps the greatest benefit to be anticipated will be general acceptance of the need for continuous adjustment of such regulations in accordance with sound principles, replacing sporadic drives to tighten up requirements in response to some disaster and subsequently to relax them for reasons of economy. Continuous attention to improvement in requirements is the way in which real progress should be made in so serious a matter as public safety. 